\title{
Wearable Cane and App System for Improving Mobility in Toddlers/Pre-schoolers With Visual Impairment
}

\author{
Grace Veronica Ambrose-Zaken ${ }^{1 *}$, Mohamad FallahRad ${ }^{2}$, Henry Bernstein ${ }^{2}$, \\ Robert Wall Emerson ${ }^{3}$ and Marom Bikson ${ }^{2}$ \\ ${ }^{1}$ Hunter College (CUNY), City University of New York, New York, NY, United States, ${ }^{2}$ Department of Biomedical Engineering, \\ The City College of New York, New York, NY, United States, ${ }^{3}$ Department of Blindness and Low Vision Studies, Western \\ Michigan University, Kalamazoo, MI, United States
}

Children with congenital severe visual impairment and blindness (SVI\&B) are at greater risk of developing delays in motor and other developmental domains. This report describes a series of experiments conducted to evaluate a novel wearable cane and mobile application system prototype. The wearable cane and application system was tested on ability to (a) provide hands-free autonomous arc able to detect obstacles,

OPEN ACCESS

Edited by:

Graeme Douglas,

University of Birmingham,

United Kingdom

Reviewed by:

Onder Islek,

Aksaray University, Turkey Rachel Hewett,

University of Birmingham,

United Kingdom

*Correspondence:

Grace Veronica Ambrose-Zaken gambrose@hunter.cuny.edu

Specialty section:

This article was submitted to Special Educational Needs,

a section of the journal

Frontiers in Education

Received: 20 September 2018 Accepted: 09 May 2019 Published: 29 May 2019

Citation:

Ambrose-Zaken GV, FallahRad M, Bernstein $\mathrm{H}$, Wall Emerson $R$ and Bikson M (2019) Wearable Cane and App System for Improving Mobility in Toddlers/Pre-schoolers With Visual Impairment. Front. Educ. 4:44 doi: 10.3389/feduc.2019.00044 level, and surface changes; (b) integrate into indoor/outdoor activities of a specialized pre-school for learners with SVI\&B; and (c) be adopted by families, professionals and learners with SVI\&B as a safe mobility solution. Sixteen stakeholders and 34 children under five with SVI\&B evaluated the prototype system.

Results: The project successfully created a hands-free wearable white cane that provided students with SVI\&B under age five with next step warning when walking across a variety of terrain. Pre-school participants with SVI\&B easily adopted the wearable cane into their activities with minimal to no prompting or instruction. The P20 prototype scored well across usability features, including maintaining consistent, hands-free, autonomous arc. The invention of a hands-free mobility tool was a significant outcome of this project. These data support that autonomous arc has the ability to provide developmentally appropriate safe mobility solution for toddlers with SVI\&B.

Keywords: visually impaired, blind, wearable white canes, orientation and mobility, safe mobility, early intervention, pre-school

\section{WEARABLE CANE AND APP SYSTEM FOR IMPROVING MOBILITY IN TODDLERS/PRE-SCHOOLERS WITH VISUAL IMPAIRMENT}

There is overwhelming evidence to support the conclusion that low vision and blindness negatively impact the dynamic stability of children even when walking in safe and uncluttered environments (Hallemans et al., 2011). Hallemans et al. (2011) reported that children with severe visual impairment and blindness (SVI\&B) walking freely (without mobility tools) through open space exhibited smaller stride length and more plantar foot contact due to "the problems faced by sensory deprivation to maintain stability" (p. 551). Studies have confirmed that when participants with SVI\&B walked without mobility tools they demonstrated slower walking speeds (West et al., 2002), 
greater likelihood of incident mobility (e.g., tripping over obstacles) (Deshpande et al., 2011; Subhi et al., 2017), and greater risk of developing a mobility disability (Salive et al., 1994).

Gazzellini et al. (2016) compared the motor results of sighted children (aged 3.5-12.8 years) who walked through a room (three with eyes closed and three with eyes open) with six blind children aged 3.5-13.2 years. They concluded, "The atypical gait of children with congenital blindness investigated in the present work should be explained by a single mechanism ...the lack of anticipatory control..." (p. 2626). The long white cane is the most recognized form of anticipatory control used by individuals with SVI\&B. However, the safety of children under five with SVI\&B walking with long canes is not well-researched.

Studies of long cane effectiveness (e.g., for detecting dropoffs) were conducted only with adult cane users-those who were able to employ a syncopated cane arc and had experience responding to long cane tactile feedback for safety and route planning (Bongers et al., 2002; Kim et al., 2017). Although no long cane studies evaluated cane skills of pre-school or toddler subjects; when one considers the mechanics of the long cane technique needed to obtain safe mobility, children under five with SVI\&B are at a distinct physical and cognitive disadvantage when they attempt to obtain safe mobility from a long cane.

One essential challenge for long cane use by young children is in their inherent toddler gait. St. Onge et al. (2007) had sighted toddlers and college-aged teachers wear accelerometers during movement activities. They found toddlers' average acceleration velocity was equivalent to $3.1 \mathrm{~m} / \mathrm{s}^{2}$ compared to college-aged adults $1.9 \mathrm{~m} / \mathrm{s}^{2}$. The minimal recommended walking speed to cross streets within the green-yellow phase of pedestrian lights is only $1.2 \mathrm{~m} / \mathrm{s}^{2}$ (Eggenberger et al., 2017). This suggests that adult long cane users need between one and two cane swipes per second to achieve a syncopated cane rhythm.

On average, toddlers higher cadence ( $\sim 2.93$ steps per minute), means that to obtain a syncopated cane arc, toddlers would need to move the long cane back and forth approximately three swipes per second; an extraordinarily fast cane rhythm that would be very difficult to maintain for any toddler (Leversen et al., 2012). Even after orientation and mobility (O\&M) instruction and consistent reminders of proper cane position, most learners under five with SVI\&B using long canes walked with "broad areas of the body unprotected" (Anthony et al., 2004 p. 29).

Despite the link between SVI\&B and need for anticipatory control to reduce mobility incidents (Deshpande et al., 2011; Subhi et al., 2017); there is an open question as to the educational benefit of "falls" and direct bodily collisions experienced by learners with SVI\&B (Hatton et al., 2013). At what point are these intensive, sudden, and unavoidable collisions counterproductive to development in toddlers whose vision impairment makes it impossible for them to learn how to avoid moving collisions?

As sighted children mature, they fall less often. A study of the spontaneous movements of 151 sighted infants (11-19 monthsold) revealed that novice walkers fell less than expert crawlers. Further, the more steps sighted toddlers walked, the less they fell and the better their gait, pace and obstacle negotiation skills were in cluttered and open settings (Adolph et al., 2012). The authors concluded that sighted toddlers walked more because, for them, walking was a safer and more efficient way to move about.

Pre-schoolers with SVI\&B tend to remain stationary and engage in solitary play in pre-school settings especially when compared to their sighted peers (Celeste, 2006; Celeste and Grum, 2010). We believe that to encourage freedom of movement, learners under five with SVI\&B need access to a system of safe mobility that relies on their strengths to detect vital path information, such as their ability to learn to interpret tactile, haptic, kinesthetic, proprioceptive, and auditory feedback as they navigate their environments. Children under five need a new mobility solution that allows them to explore with confidence.

\section{Wearable Cane and App System}

The theory in support of the Wearable Cane and App (WCA) System is that children under five with SVI\&B need a developmentally appropriate mobility tool, one that offers a hands-free, autonomous cane arc. We define an autonomous arc as a polygonal-shape that provides two-points of contact and two-step preview while in a fixed position. The purpose of this paper is to report the design and feasibility/usability validation of the WCA prototype system. The City University of New York Institutional Review Board approved all research. Written informed consent was obtained from all adult participants and from the parents of all non-adult participants.

The experimental series addressed four questions:

1. Wearable Cane Usability and Feasibility: Will it be feasible to design a wearable cane prototype that provides autonomous anticipatory control while allowing natural movement during typical toddler ambulation?

2. How will the wearable cane prototype be integrated into a specialized pre-school for learners with SVI\&B?

3. When used by a pre-schooler with SVI\&B, how does a wearable cane compare to a long cane on route behavior and percent of time cane tips are positioned two-steps forward of the trailing foot?

4. How will stakeholders (family and educators) evaluate WCA System Usability?

\section{EXPERIMENT 1-FEASIBILITY/USABILITY OF WEARABLE CANE PROVIDING HANDS-FREE AUTONOMOUS ARC DURING AMBULATION}

\section{Background}

Several specialized pre-schools and providers of early intervention (EI) services distributed flyers about the project to their families. The purpose of the study was to rapidly make and test wearable cane prototypes. Toddler and pre-school learners wore the cane prototypes in authentic settings.

\section{Method}

\section{Sample}

Four male and two female participants with no disabilities (aged 18-72 months $\overline{\mathrm{x}}=36.33$ ) and six participants ( 3 male, 3 
TABLE 1 | Toddler cane usability features and goals.

\begin{tabular}{|c|c|}
\hline Usability features & Usability goals \\
\hline 1. Maintains structural integrity & $\begin{array}{l}\text { Toddler Cane maintains structural integrity } \\
\text { during all testing periods }\end{array}$ \\
\hline 2. Maintain forward position & $\begin{array}{l}\text { Cane returns to forward position when clear of } \\
\text { obstacles }\end{array}$ \\
\hline 3. Recovers from obstacles & $\begin{array}{l}\text { Cane returns to forward position when clear of } \\
\text { obstacles }\end{array}$ \\
\hline 4. Surface change detection & $\begin{array}{l}\text { Cane tip locates change edge two steps } \\
\text { ahead; two-points of contact provide side } \\
\text { surface change detection }\end{array}$ \\
\hline 5. Rough surface & $\begin{array}{l}\text { Cane tips glide with sufficient response over } \\
\text { rough surfaces (e.g., grass, cobblestone, thick } \\
\text { carpet, etc.) }\end{array}$ \\
\hline 6. Traverses bumps & $\begin{array}{l}\text { Toddler Cane can traverse bumps (about one } \\
\text { inch) with relative ease }\end{array}$ \\
\hline 7. Traverse level change/stairs & $\begin{array}{l}\text { Toddlers/Adults can maintain cane in an } \\
\text { appropriate, safe position while traversing stairs }\end{array}$ \\
\hline 8. Approach stationary objects & $\begin{array}{l}\text { Toddler is able to bring toes up to base of } \\
\text { stationary object }\end{array}$ \\
\hline 9. Narrow passageways & $\begin{array}{l}\text { Cane grips can twist cane shaft and lift cane } \\
\text { shaft as needed by adult/wearer to negotiate } \\
\text { narrow path }\end{array}$ \\
\hline
\end{tabular}

female) with SVI\&B (aged 28-48 months, $\bar{x}=33.37$ months) wore multiple wearable cane iterations, named P2-P20, over 14 weeks. Three participants had cortical visual impairment (CVI), two had optic nerve hypoplasia $(\mathrm{ONH})$, and one participant's vision impairment was undefined; two participants had motor impairments limiting their ability to walk without support. One participant used a gait-trainer when wearing the cane. Sighted subjects tested prototypes as the testers only needed to be the right size (age) when testing whether the device maintained its position forward of the subject when worn during ambulation. Written informed consent was obtained from all adult participants and from the parents of all nonadult participants.

\section{Measure}

The feasibility/usability tests evaluated wearable cane prototypes as assembled (wearable canes) and as individual parts (e.g., belt, cane shafts) against nine Usability Feature Goals (UFGs) (see Table 1). The UFGs developed for this study were based on the expected functioning of a long white cane when used by an expert, adult cane user (Bongers et al., 2002; Kim et al., 2017).

A research associate was trained on the scoring system. Interrater reliability was established between the coder and research manual to be $97.3 \%$. The coder used one or more videos clips of the participants wearing the prototype to evaluate prototypes on the following UFG scoring rubric: [Blank] = Not Observed, $0=$ Unsuccessful Attempt, 1= Partially Successful, 2 = Successful with Adult Guide, 3 = Successful Attempt, 4 $=$ Exceeds Expectations. Each prototype was given a final UFG score which was the sum of the nine Max UFG scores. The total Max UFG score could be blank or a number between 0 and 36 .

\section{Procedures}

The feasibility and usability tests consisted of videotaped trials of individual participants wearing cane prototypes on wide, tile hallways and in a lab fitted with a "kid friendly" obstacle course, and outside on sidewalks and in a playground. Participants and their family members were shown the wearable cane and asked if it could be positioned correctly on the child with SVI\&B. Family members identified motivators and provided critical observations of the participants during the trials. While wearing the device, participants were encouraged to walk to locate toys which required them to traverse varying levels, surfaces and obstacles in their path. An O\&M specialist facilitated the participants' interaction with the test routes. The number and distance of routes was dependent on the functioning of the prototype; the better the prototype functioned the longer the test.

\section{Results}

Through iterative design and validation, we evaluated 20 prototypes over 14 weeks. During the testing, if a given prototype did not provide hands-free autonomous arc it was triaged and not tested further.

Figure 1 describes the key features of the prototype design that were evaluated. Key design decisions centered around design seven components. (1) Vest (V): vest/suspenders were explored in a variety of forms, but were omitted in P20 prototype. (2) Grip (G): The grip types included a dedicated plastic piece that stuck up separately from the shaft. The P20 design grip mirrors a long cane as it was integrated into the shaft. (3) Double Waistband (DW): The double waistband innovation was present in the original P1 design and it allows the hands-free autonomous arc. The P20 DW consisted of a comfortable belt that rested on the subjects' hips and an outer 3-D printed CShaped shell that connected to the inner belt. Designs evaluated to connect the inner and outer waistbands included (on P20) a taught elastic cord and, subsequently, a magnet connection that omitted the elastic. The magnet connection enabled subjects to wear the inner belt separately from the outer plastic shell. (4) Single Waistband (SW) attempted to use only one belt connection with the cane shafts. (5) Shaft (S) In order to maintain the cane shaft and grips forward of the subjects, the length of the two cane shafts established the angle of incidence and distance of the cane tips and housing. (6) Tips (T) the cane tips supported travel across a range of expected terrains. The team experimented with standard roller tips, custom globeshaped tips, and several omni-directional wheels. P20 cane tips were custom ball bearings. (7) Housing $(\mathrm{H})$ : The team designed various housings needed to connect the cane tips to the shafts. The P20 design incorporated a 3-D printed housing that covered the ball bearings. It extended forward and metal shields were affixed to the bottom of the housing where it contacted surfaces. This design proved light-weight, highly adaptive over a wide range of terrains, and provided useful mechanical (and also audible) feedback to subjects.

Prototypes that provided hands-free, autonomous arc received scores of 25 UFG and higher, because they did not drift, traversed descending stairs, and moved easily over objects $<1$ inch high and across rough, rocky and uneven terrain. 


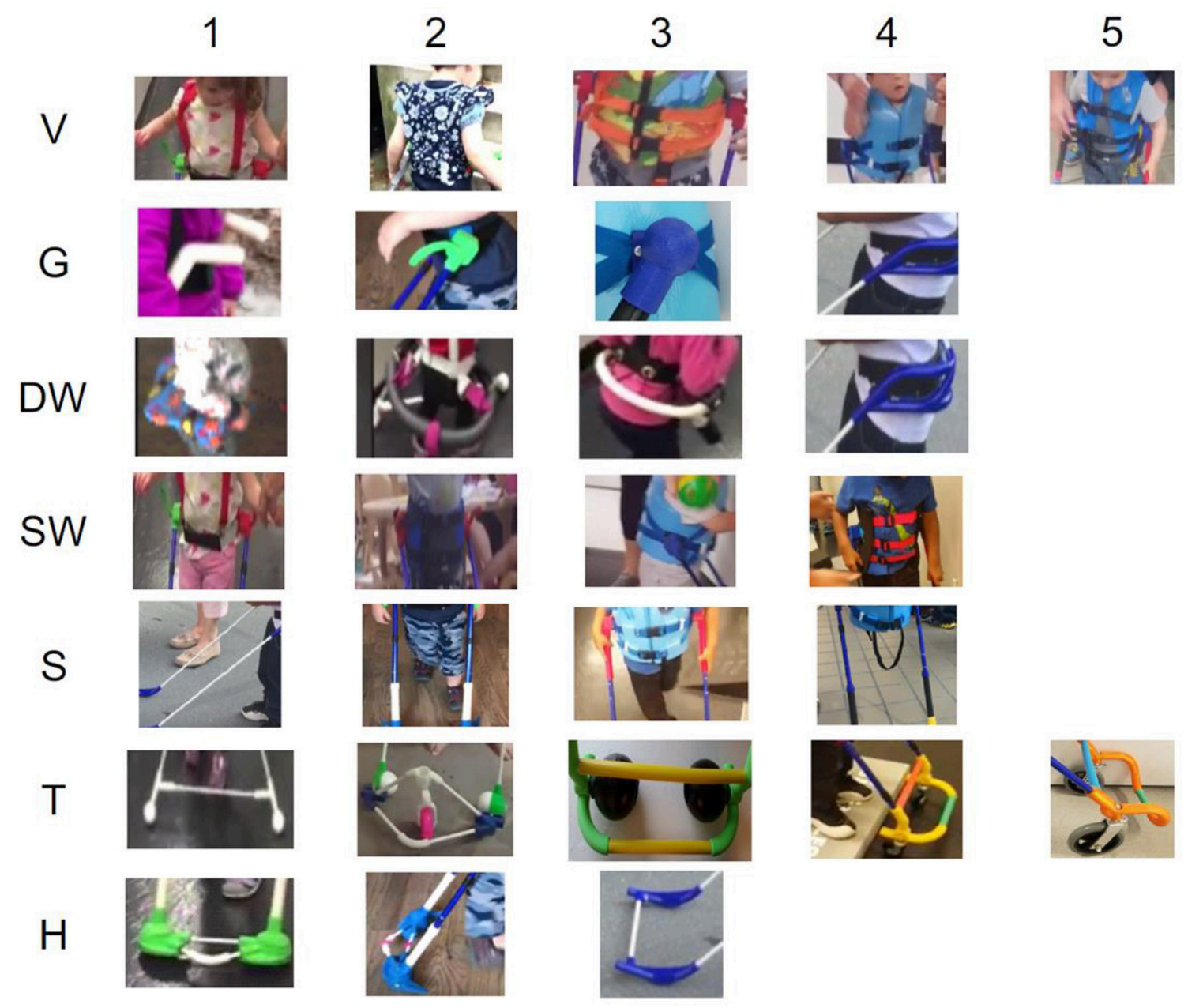

FIGURE 1 | Design components used during the rapid prototyping phase.

Figure 2 P20 design. Prototype P20 (MaxUFG = 29) had the highest Max UFG score of the 20 prototypes tested. P20 consisted of a double waistband, graphite shaft, and ball bearing tips. It was lightweight and remained forward of the subjects' paths on most terrain and required minimal to no manipulation by the subjects. Families reported that when toddler and pre-school participants wore P20 they were walking, running, and playing more age appropriately.

For one subject, a physical therapist (PT) of a participant with lower quadrant field loss due to CVI, attributed wearing the P20 prototype cane to observed improvements in gait and posture. Prior to the trials, the child's PTs did not understand why the subject walked bent over although she had the strength to stand up straight. After evaluating the subject with CVI walking fully erect when wearing the toddler cane the PT concluded, her gait deviations were vision related and reduced the number and size of orthotic interventions prescribed for the student. The physical therapist agreed that wearing her cane immediately improved her posture and gait during ambulation.
Subjects with SVI\&B appeared to enjoy wearing prototype P20 and they appeared to obtain physical and sensory benefits ambulating behind a hands-free autonomous arc. Therefore, P20 was selected for further feasibility/usability testing.

\section{EXPERIMENT 2- HOW WILL THE WEARABLE CANE PROTOTYPE BE INTEGRATED INTO A SPECIALIZED PRE-SCHOOL FOR LEARNERS WITH SVI\&B?}

\section{Background}

With such an innovative approach to the O\&M of children under five with visual impairment, it was important for non-biased research protocols, naturalistic observation of the reaction, interpretation and integration of this new technology by the students, their teachers and family members. The research began with the research area, wearable cane potential ability to solve the problem of unsafe mobility, but without specific research 


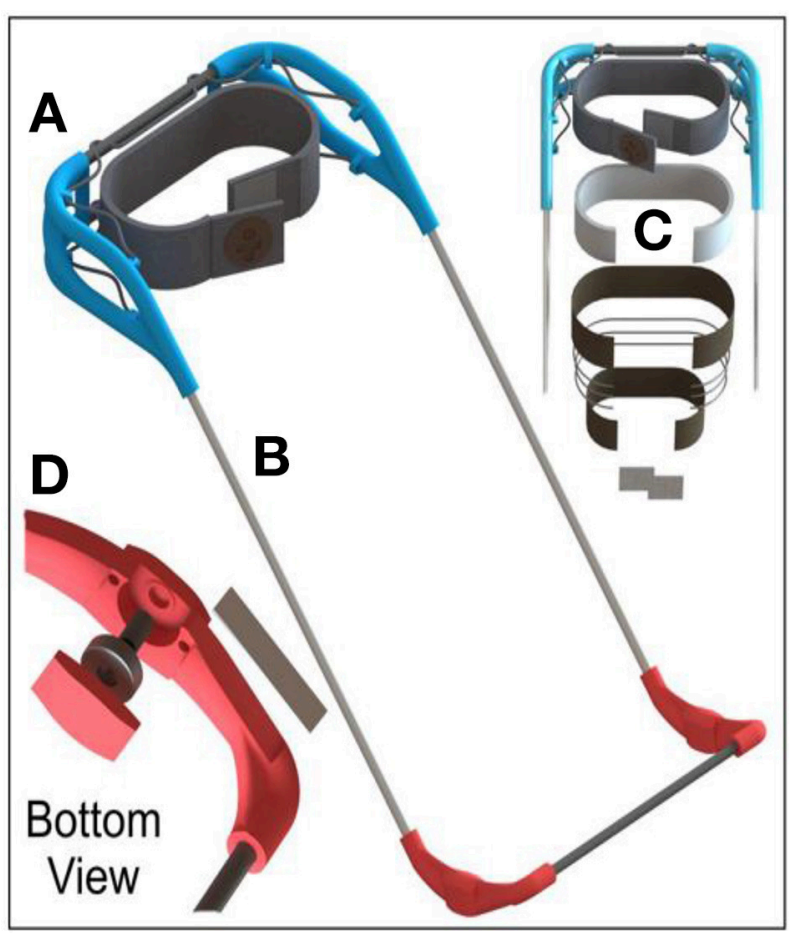

FIGURE 2 | Rendering of the P20 prototype wearable cane. (A) Plastic handles. (B) Carbon fiber tubes. (C) Layers of the belt. (D) Ball bearing, Shaft, steel plate \& plastic parts.

questions, and initial data collection was unstructured. Several schools volunteered and the first school selected, participation was voluntary. Two O\&M specialists and two teachers of learners with visual impairment (TVIs) volunteered to take part. Written informed consent was obtained from all adult participants and from the parents of all non-adult participants. Following measurements of subjects by on-site care-givers, individualized toddler canes were fabricated for evaluation. The subjects, teachers and family members were provided with basic instructions on the use of the wearable cane and were observed via video as they integrated P20 into different activities.

\section{Method}

\section{Sample}

The pre-school participants were severely visually impaired and blind, ambulatory, attending a specialized pre-school for learners with SVI\&B and had participated in daily O\&M instruction using the long cane since starting pre-school. The five participants were selected by their teachers to be included; their teachers reported the participants exhibited mild to severe developmental delays in motor, concepts, language, and social skills. However, no formal tests were conducted by the project.

\section{Measures}

The current study used the grounded theory method (Glaser and Strauss, 1967; Glaser, 1998) to explore outward behaviors of pre-school staff, families, and learners with SVI\&B after introducing prototype wearable white canes. Data collection involved videotaping the subjects during O\&M sessions, free play and moving about the school building and various school rooms (classrooms, gross motor, music), as well as during several field trips off school grounds. The teachers were interviewed and comments from the parents and other staff who observed the students regularly and when wearing the canes were also collected and analyzed.

Analysis began with the first experience of teachers witnessing pre-school learners with SVI\&B as they moved about the environment wearing their canes (singly or in small groups) and observing the pre-school students individually as they wore the canes and at other times. The researchers' interpretations were further grounded in the comments of the families and professionals who were present during the activities. Participants and data selected gave comparisons of subject functioning with and without the wearable cane. Theoretical sampling guided the selection of those learners with SVI\&B who were not able to employ long canes for safe mobility but who appeared to thrive when wearing P20.

\section{Procedures}

Custom-fitted wearable canes were presented to nine participants with SVI\&B during daily activities $(N=27)$ within 1 week. Eight of the nine participants (aged 38-47 months $\mathrm{x}=40.5$ ) wore the prototype cane; of those six subjects wore the cane prototypes daily for multiple activities and two subjects were took longer to begin wearing the cane and wore it three times to complete increasing longer routes. One participant, who had severe tactile defensiveness to new objects, did not wear the cane.

Over the week, there were multiple in-person opportunities to discuss the P20 including asking open-ended questions and following-up on comments made by professionals and family members during previous activities. In addition, the teachers and the principal were interviewed for an hour as a group; and these interactions were videotaped and used in data analyses. Further, follow-up e-mail correspondence with professionals were conducted at 1 and 2 months intervals post-intervention.

Participants were encouraged to conduct their activities as they would on a typical school day, only with the addition of the wearable canes at intervals and for activities chosen by the teachers. The pre-school had pre-established mobility tool use patterns; the students with SVI\&B used mobility tools during structured O\&M lessons and in the hallway. Mobility tools were stored in a cane holder near the classroom door upon entering classrooms. Participants were observed walking independent of mobility tools when moving about classrooms, playgrounds, gross motor rooms, music rooms, and during other structured and unstructured activities at school.

The wearable cane was introduced to nine 3-year-old subjects with SVI\&B during their individual O\&M lessons and some also wore it in class and on field trips. The activities took place on a variety of terrain including: in hallways with tile floors, school playground with spongy walkways and sand pit, outside on cement sidewalks, asphalt streets, gravel walkways, wooden shavings, ungraded dirt road, and in thick, uneven grass. The professionals and families were encouraged to talk freely within the subject area, raising the concerns, and resolutions they found important. 
The video coding of data progressed from open coding, where all data were included; to selective coding, where only the data that related to the emerging core category were coded; and then finally to theoretical coding, where the relationships between categories and properties of data were explained. During analysis, three questions were asked: What is the main concern? How is it being resolved? And what category, or property of a category, does the comparison represent (Glaser, 1998)? Observations of subjects formed data categories; subsequent data were selected to help saturate categories, and their properties, in a process known as theoretical sampling. The following theory resulted from coding the feasibility/usability trial videos.

\section{Results}

\section{Resultant Grounded Theory}

Observations of the subjects (pre-schoolers, their teachers and families) led to the following grounded theory on the first prototype wearable cane: Learners with SVI\&B will easily adopt wearing a device that provides safe mobility, aka consistent next step warning. Seven pre-school learners with SVI\&B showed a preference to wearing the cane than using a long cane or no cane. They also proved a capacity to manipulate the wearable cane effectively to locate clear paths, traverse drop-offs, and navigate uneven terrain while maintaining above $90 \%$ next step warning. The pre-school learners did not show the ability to obtain consistent, next step warning when employing their long canes. After the week-long trial, the pre-school learners with SVI\&B appeared to thrive when wearing their canes, the video captured multiple instances of them responding positively to the information received when wearing their canes, and few instances of the pre-school learners having any adverse effect from wearing their canes. The pre-schooler seemed to easily resolve how to wrest the cane shafts away from furniture or other obstacles to continue on their way.

When adults requested the cane be taken off; pre-schoolers' with verbal communication skills; declined to take it off, asked for the cane to be put back on, asked where the cane would be stored, and after walking without it, independently picked up the cane and asked to start wearing the cane. The idea of having a cane all the time was adopted by one student during the weeklong study; she possessed sufficient language skills to make her wish to keep wearing the cane very clear.

The teachers attributed similar characteristics and uses to the wearable cane as to the long cane. This meant that the routines and environments adults encouraged students to employ long canes were the same routines and environments where adults included the prototype wearable canes.

Four distinct patterns of mobility-related student and professional behaviors, or strategies, emerged from the data: (1) Pre-school learners with SVI\&B functionally used the wearable cane, (2) O\&M specialist changed their instructional content and positioning when teaching a child wearing a cane, (3) Preschool participants demonstrated a preference for wearable cane to be remain on, and (4) School staff who responded sought to define the role of the wearable cane within specialized pre-school students with SVI\&B whose Individualized Educational Goals are for mastery of the long cane-each addressed below.
1. Pre-school learners with SVI\&B functionally used the wearable cane. Pre-school participants with SVI\&B (and without tactile defensiveness) easily adopted the wearable cane into their activities with minimal to no prompting or instruction. The participants were observed both relying on the handsfree autonomous arc and manipulating the cane arc, at will to locate a clear path. The participants would let go of the cane shafts to locate objects, for balance, or to carry objects as they walked. When participants' hands were empty, they adopted two common hand positions; either they were observed to lightly contact the cane shafts with one or both hands or they fully grasped the cane shafts with one or both hands. The more motor skill delays demonstrated by the participant, the more they relied on the hands-free autonomous arc and did not use their hands to steer the wearable cane.

Pre-school participants steered the cane shafts to locate clear paths, to negotiate rough terrain, or to bang the cane against objects or surfaces. Participants easily incorporated the tactile feedback from the cane tips to alter their course. For example, they slowed their pace in uneven terrain and stopped when the cane tips dropped lower indicating elevation changes. Most participants appeared to lift and lower the cane shafts at will. Some participants pushed the cane shafts side to side and up and down to produce added sensory feedback. Some appeared to be able to control the cane tips to lightly trail over the top of rough surfaces as they moved.

When wearing the cane, pre-school subjects with SVI\&B experienced consistent tactile next step warning. They were stopped before tripping on objects one-inch or taller. They were prevented from bodily contacting walls, they were able to easily determine change in surfaces in order to independently stay on sidewalks.

2. O\&M specialist changed their instructional content and positioning when teaching a child wearing a cane. The O\&M instructors were observed teaching wearable cane strategies to their students. For example, they encouraged students to let go of the cane while walking. O\&M specialists also encouraged participants to run when wearing their canes. In addition, instructors were observed reinforcing many standard long cane techniques with the wearable canes. For example, instructors reminded students to keep the cane tips on the floor, observed and intervened as necessary to aid their students in traversing up/down stairs, doorways, surface changes and when investigating and/or circumventing obstacles.

Instructor positioning changed, typically when teaching preschool learners to maintain cane arc, the instructor must bend down or scoot on a wheeled-stool. When wearing the canes, instructors most often stood erect, were able to observe from greater distances and allowed the pre-school participants greater freedom to explore. The pre-school students demonstrated the capacity to navigate more safely by independently detecting and then responding to the path information (e.g., obstacles in the path) obtained through the cane.

The O\&M specialists praised their students for independently manipulating their wearable canes. The teachers commented that when wearing the cane, they observed improvements in 
their students' gait, posture, and independence. For example, a frequent observation made by all the O\&M specialists was their students were walking in straight lines, they stopped less often and needed less prompting to keep up with the group. Example statements made by the adults were, "she's walking straight"; "she never walked the entire way to the park and back before today"; "her gait is improving," "her arm swing is becoming more natural" and "I've never seen her run before".

Also, the O\&M instructors appeared to either possess or quickly adopted the vocabulary and lesson objectives needed to integrate the wearable cane into their lessons. In the wearing cane conditions, the O\&M instructors and TVIs' lessons were focused on concept development. The teachers grew confident in their students' ability to respond correctly to feedback from their wearable canes; this was demonstrated by the ever increasing distance between the instructor and the student.

3. Pre-school participants demonstrated a preference for wearable cane to remain on. The O\&M specialists routinely and spontaneously asked the students with SVI\&B if they would like to take off their wearable canes. O\&M specialists asked this question each time participants arrived at a classroom or the playground picnic table. It was asked mid-activity; when students were moving about ungraded dirt roads and through overgrown grass and uneven corn fields perhaps because the appearance of a student using a wearable cane appears more abrupt when it encounters obstacles 1 " or taller blocking their forward progress.

When the O\&M specialist asked the participants outside in the corn field and ungraded dirt road - two participants agreed to take off their canes, but then, almost immediately, asked to put them back on again. On a sidewalk-one participant declined to take the cane off. At the playground picnic table-all participants agreed to take off their wearable canes to sit down for a snack. Afterwards, two participants requested their canes be put back on before they headed onto the woodchip surface of the playground. On the playground, the O\&M specialist routinely asked if these participants wanted to take off their canes when using the equipment. One participant refused, and the cane remained on until she got on the swings, she swung by herself for the first time that day and requested the cane be put back on afterwards. The other participant agreed, and the cane remained off, however as observed by the camera, she independently retrieved the wearable cane and began pushing it in front of her around the equipment.

When the O\&M specialist asked the participants to remove the canes when inside in the classroom, all the participants eventually agreed to take off their canes. One participant asked to be allowed to keep it on, but after repeated requests she held on to it and asked to be told where the wearable cane was going to be stored. During a crowded, unstructured party in a classroomall participants agreed to remove wearable canes and place them next to the long canes against the walls of the room. During the dance party these students either interacted with a guide or remained seated.

Some participants demonstrated a sincere preference for wearing their canes. One participant with low vision cried until it was determined that she was worried that she was not going to be able to take the cane home with her. She stopped crying when she was told she would be allowed to wear her cane home. She returned to school with it each day of the trials and wore it during the school day. This participant was reported to be regularly wearing her cane at 1- and 2-month follow up.

In the classroom, another student with low vision and hemiplegic paralysis that prevented her from using long cane technique, reacted positively when she was told she was going to put on the wearable cane back on; she moved quickly to where the cane was stored and helped the teacher in putting it on her. On another occasion, she was observed tugging at the wearable cane, after it had been removed from her and they were walking on a grassy surface, on a third occasion she was able to verbally request the cane be put back on her.

The final 2 days of the testing, the project team encouraged TVIs to allow students to wear their canes during classroom activities and three pre-schoolers were observed wearing P20 in class: (a) two participants wore the cane during circle time which required they move back and forth from chair to the magnet board/basket, the cane allowed them warning of tripping hazards and to locate their chairs; (b) moving through the classroom, the cane contacted furniture providing consistent warning of hard to see objects; (c) two learners also sat at their desks to complete seat work while wearing the cane, another sat in group music wearing her cane. Having the cane on all the time allowed may have added to their feelings of well-being in the security of their ability to independently find and avoid hazards in the path ahead which is a critical skill for encouraging solo independence. Children's ability to freely move about with safe mobility at any time are critical for development and well-being.

4. School staff who responded sought to define the role of the wearable cane with pre-school students with SVI\&B whose Individualized Educational Goals are for mastery of the long cane. After observing their students wearing the device, the school personnel found their pre-school learners with SVI\&B appeared to rapidly improve in their ability to respond to the feedback from the wearable cane. The O\&M specialists observed that students wearing the cane were walking more direct paths and were walking with more erect postures. They reported that students were noticed to have walked further on their own, when typically, with a long cane, they would have opted to ride in the wagon, students wearing their canes walked the entire route to the playground and back. The O\&M specialists also observed that when wearing the canes, the students had greater interest in plants and peers during the walk, compared with previous walks using long canes. However, at the end of each experimental session, the adults removed the canes and returned the students to previous state of walking without mobility tools inside their classrooms.

When asked to define the role of a wearable cane, a school administrator entered, "a wearable cane was a tool to be considered as one more option among the current mobility tool options used during O\&M instructional activities." The administrator explained that his school was operating under a 
rule that only children able to use a long cane when they enter elementary school received O\&M services. Therefore, he did not want to do anything to interrupt his students' progress learning to use their long canes.

All study participants were offered to retain their wearable cane after the trial and O\&M support in use. However, none of the instructors agreed with the premise that blind preschool children would benefit from wearing their canes most of the day.

Follow-up after 1 month, an administrator responded, "We look at the cane as a great tool and the O\&M's are still looking at it on students and various times of the day and schedule. But teachers are not putting them on yet without O\&M. O\&M are looking into when they would recommend wearing it and during what parts of the day. Once they are done figuring out that part teachers will follow through with recommended times."

Follow-up 2 months later the 10 pre-school participants who verbally requested they continue wearing their canes during the study were reported by O\&M specialists to be "still successfully wearing their canes" at school and home. O\&M specialists reported that six participants with low vision were not currently using the wearable cane during O\&M lessons or unstructured travel activities, the O\&M specialist reported visual skills instruction was consistent with their IEP objectives.

\section{EXPERIMENT 3- WHEN USED BY A PRE-SCHOOLER WITH SVI\&B, HOW DOES WEARABLE CANE COMPARE TO LONG CANE ON ROUTE BEHAVIOR AND PERCENT OF TIME CANE TIPS ARE POSITIONED TWO-STEPS FORWARD OF THE TRAILING FOOT?}

\section{Background}

The first pre-school student to wear the cane was selected for this single-subject study. Her significant vision impairment interfered significantly with her safe mobility.

\section{Method \\ Sample}

The participant was a 39-month old girl with severe VI who attended a specialized school for learners with VI. She ambulated with a slow pace and her gait was wider than typical base. The participant demonstrated age-appropriate cognition and somewhat delayed communication skills in the form of mild echolalia. The participant had a history of using a long cane during O\&M lessons and other structured outings. She typically traveled independent of a mobility tool at home, in classrooms, and during unstructured indoor and outdoor activities.

\section{Measure}

The video footage was analyzed for evidence of safe mobility as well as amount and content of subject vocalizations. In the long cane condition, cane safety was tabulated by grouping the total number of steps by the categories "safe," "unsafe," and "partially safe" cane tip position. A "safe cane position" was coded each
TABLE 2 | Number and percentage of steps taken and cane tip placement.

\begin{tabular}{lcc}
\hline & No. & $\%$ \\
\hline Total number of steps taken with cane held in right hand & 781 & 1.00 \\
cane tip pushed in front of right foot & 133.5 & 0.17 \\
cane tip wide on right side & 277.5 & 0.36 \\
cane tip center of body & 67.5 & 0.09 \\
cane tip behind body & 101.5 & 0.13 \\
cane tip not in contact with the ground & 141.5 & 0.18 \\
cane tip in front of left foot & 45.5 & 0.06 \\
cane tip wide on left & 14 & 0.02 \\
Total number of steps taken with cane held in left hand & 369 & 1.00 \\
cane tip pushed in front of right foot & 15 & 0.04 \\
cane tip wide on right side & 0 & 0 \\
cane tip center of body & 17 & 0.05 \\
cane tip behind body & 17 & 0.05 \\
cane tip not in contact with the ground & 82 & 0.22 \\
cane tip in front of left foot & 97.5 & 0.26 \\
cane tip wide on left & 129 & 0.35 \\
\hline
\end{tabular}

time the cane tip swept the area 2-steps ahead of the trailing foot. A "partially safe cane position" occurred when the cane was in diagonal position (cane tip pushed forward in front of only one foot) for multiple paces and when the cane was pushed forward of the mid-line of her body. "Unsafe cane position" was coded anytime the cane tip position was held vertical or above the ground, pushed wide left, wide right, or dragged behind the participant.

Participant and adult total vocalizations and incidence of vocalizations were collected and analyzed. The content of each participant and adult speech was also examined and grouped by content theme. Total vocalizations was defined as the number of spoken sentences and total instances of vocalizations was defined as the number of times speech occurred.

\section{Procedures}

The participant was videotaped as she walked a familiar, 0.5mile route to a nearby playground as part of a small group of teachers, teacher aids, and peers. The route consisted of four surfaces: Sidewalk, asphalt, gravel path, and dirt path. A MANOVA indicated surface type had no significant interaction with participant performance on the measured indicators $(\mathrm{V}=$ $0.452, p=0.33$ ). The participant walked half way using her long cane. At the mid-point, the participant switched to wearing her custom-fitted wearable cane (P20) and completed the remaining 0.25 miles of the route.

\section{Results and Discussion Cane Safety}

The total number of steps taken by the subject $(N=1150)$ and the cane tip position on each step is provided in Table 2. The subject held the cane in her right hand $(n=781)$ and left hand $(n=369)$ while walking. Figure 3 shows the percentage of time the cane tip was positioned in six zones: a. Behind/Off the ground, b. too wide on cane side, $c$. in front of cane-side foot, d. at mid-line, e. 


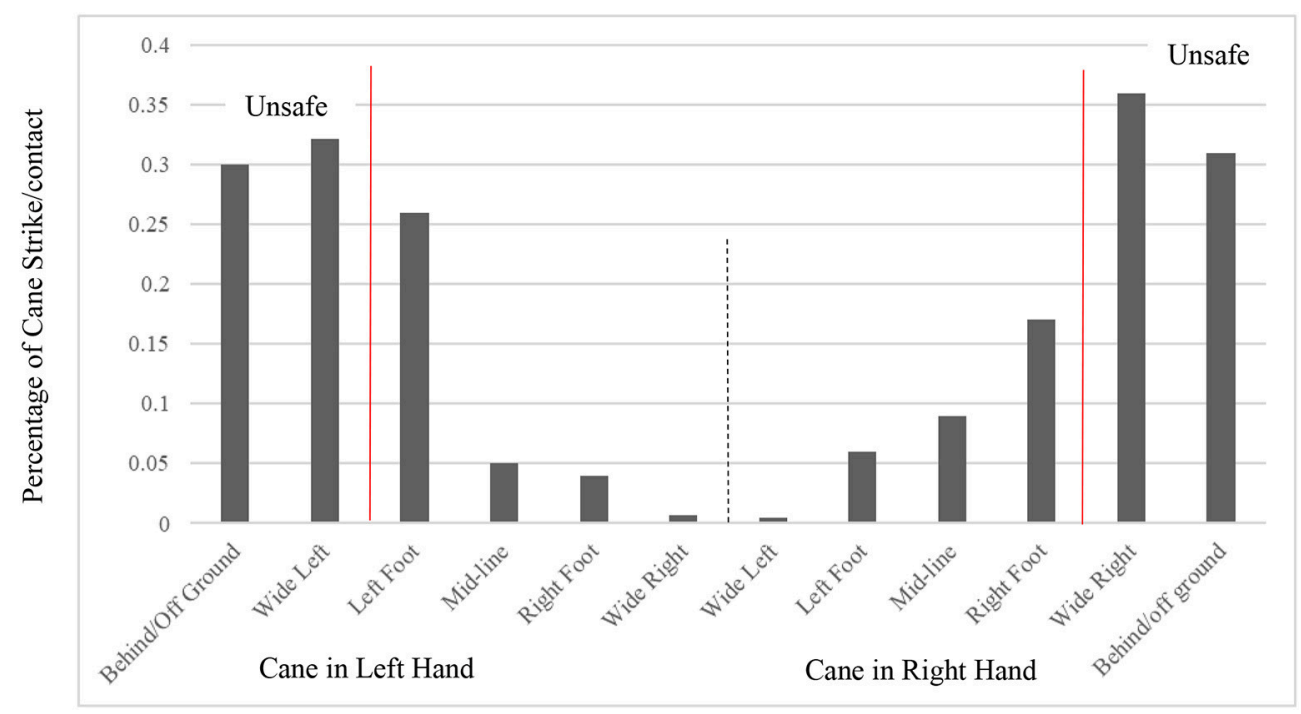

FIGURE 3 | Location of cane position. Cane tip position during 1,150 steps when long cane held in left hand ( $n=369$ steps) and right hand $(n=781$ steps). The child's cane motion positioned cane tip 65 percent of the time in an unsafe location on the cane hand side. The cane rarely (left hand, $4 \%$; right hand, $6 \%$ ) crossed mid-line to a position ahead of the opposite foot.

in front of the opposite-cane side foot, and f. too wide from body opposite cane side. The data summarized in Table 2 and graphed in Figure 3 suggests that the cane hand was predictive of cane tip position; when the cane was in the right hand, she positioned the cane tip on her far-right side or behind her $65 \%$ of her steps.

The likelihood participant's cane tip position swept the ground two-steps ahead of her next footfall were lower than the graph might reflect. For example, when held in the left hand the cane tip was in front of the left foot about $25 \%$ of the time but positioned in front of the right foot $<5 \%$ of the time. This means that about 20 percent of the time only the left foot was obtaining next step warning, the right foot was completely exposed. In the long cane condition, participant's probability was very low that the location upon which she would trod next had been checked prior by the long cane tip.

At no time during the route did the participant keep a syncopated cane arc. She often lifted the long cane off the ground to aid in her balance. In rough terrain, for example, in very tall grass the participant lifted the cane high enough to clear it of the grass forward and left of her body (cane in left hand). She then turned her body to the right (putting her back to the cane tip) and picked her way through a separate patch of tall grass.

By contrast, Figure 4 demonstrated 93\% consistent, tactile next step warning when she wore the cane. The student and the wearable cane plowed forward together. She learned to direct the cane tips to locate a clear path, at will. In the wearable cane condition, almost all of her steps were onto surfaces that had been previously swept by a shoulder width cane tip arc one inch above the ground (when rested on flat surface).

\section{Participant and Adult Vocalizations}

In the wearable cane condition, the pre-schooler with SVI\&B spoke more sentences, more frequently compared to the long cane condition $[(t=6.049, d f=65, p<0.05)]$. The content of pre-schooler's vocalizations was also very different. Table 3 suggested that in the long cane condition, the top three topics discussed by the pre-schooler were (1) questions about sensory information $(n=18),(2)$ responding to an adult $(n=15)$, and (3) the participant talking to herself $(n=13)$. Table 3 suggested that when wearing the cane, the participant's top three topics she discussed were on (1) orientation and route planning $(n=20)$, (2) mobility $(n=15)$, and (3) play statements (e.g., "I'm going to get you," $n=14)$.

The adults spoke more frequently in the long cane condition (instructor total vocalizations $t=5.69, d f=65, p<0.05$ ) and instances of speech $(t=6.062, d f=65, p<0.05)$. Table 3 indicated that in the long cane condition, most of adult speech were about participant's cane position and verbal prompts to encourage faster walking. For example, "where's your cane?," "cane in front," "sweep your cane."

Table 3 also demonstrated that there were very few cane correction statements in the wearable cane condition. Instead, the instructors engaged in meaningful interactions. For example, just before stepping down off the curb into the parking lot, the student heard the instructor kick a metal object out of the way. The student asked what it was and was told it was an old seatbelt. The student stepped down off the curb and asked to kick it. The instructor asked her to return to the sidewalk. The student walked past the instructor, located the seatbelt and kicked until she could make the noise. The instructor and she discussed the seatbelt for a moment.

In parking lot standing parallel to the sidewalk, the student indicated she heard her friends playing ahead of her, she and the O\&M specialist planned to go to them. The teacher wanted the student to walk on the sidewalk. The teacher used her hands to gently steer the student ninety degrees to face the direction of the 


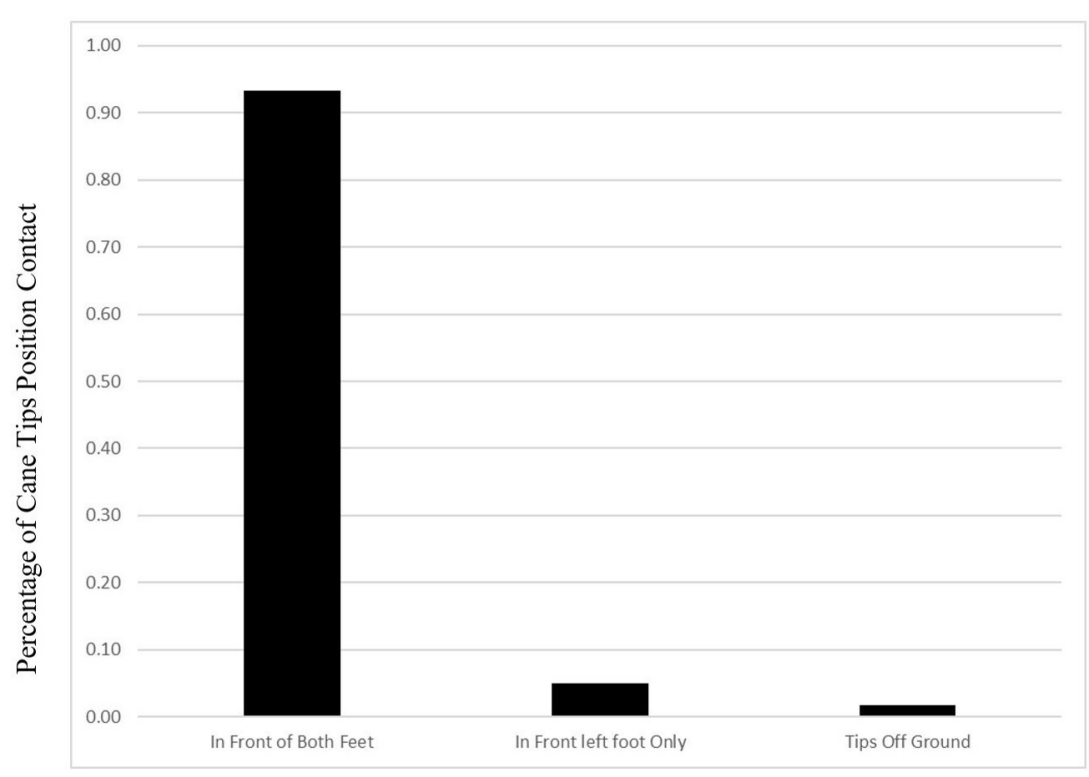

Wearable Cane Arc Position

FIGURE 4 | Autonomous cane arc positioned cane tips two-step ahead fo both feet $93 \%$ of the time ( $N=1,920$ steps).

sidewalk. The student hesitated and when the teacher prompted her to go; the student quickly turned back ninety degrees and began walking in the direction of her noisy friends. The teacher stopped her and they had a discussion about the route, the student rejecting the turn until the teacher insisted she comply. The student walked until the cane located the curb and then she asked, "is this the sidewalk?" The student's visual impairment meant she had not been able to see the sidewalk, but she could hear her friends.

When the participant used the long cane, the instructor's use of corrective statements was significantly higher than when she wore the cane $(t=4.222, d f=65, p<0.05)$. When wearing the cane, the instructors use of praise statements was significantly higher $(t=4.261, d f=65, p<0.05)$ compared to when she used the long cane. The difference was evident to the teachers as well, one teacher commented that she noticed she had repeatedly interrupted content discussions with her student to correct her long cane position.

The difference in tone between the first half and second half of the route was noticeable as well. In the first half of the route, the instructor's tone was dominated by repeated prompts and cane corrections. No matter how often the student with SVI\&B received verbal or hand over hand cane corrections, she appeared to be unable to maintain a correctly positioned long cane as she walked.

The subject with SVI\&B did not speak as often, in the long cane condition. When she did it was to herself or in response to an instructor. For example, "what's that smell?" She appeared quiet, passive and compliant.

In the wearable cane condition, the instructor's tone was friendly and playful. The subject also began initiating conversations about objects she located with her wearable cane.
TABLE 3 | Subject language content when walking using long cane and wearable cane.

\begin{tabular}{|c|c|c|c|}
\hline Long cane & $n$ & Wearable cane & $n$ \\
\hline $\begin{array}{l}\text { Initiated question about } \\
\text { sensory info }\end{array}$ & 18 & $\begin{array}{l}\text { Initiated or responded to } \\
\text { orientation and route planning }\end{array}$ & 20 \\
\hline $\begin{array}{l}\text { Responded to adult direct } \\
\text { question }\end{array}$ & 15 & $\begin{array}{l}\text { Initiated or responded to } \\
\text { concept development }\end{array}$ & 15 \\
\hline Subject talking to herself & 13 & Initiated or responded to play & 14 \\
\hline $\begin{array}{l}\text { Student declaration about } \\
\text { sensory information }\end{array}$ & 4 & General content verbalizations & 9 \\
\hline $\begin{array}{l}\text { Student declaration or } \\
\text { request-general content }\end{array}$ & 4 & $\begin{array}{l}\text { Initiated safe mobility adages } \\
\text { and warnings }\end{array}$ & 2 \\
\hline Other & 2 & Subject talking to herself & 1 \\
\hline
\end{tabular}

She talked about routes, destinations and warned others of obstacles she found with her wearable cane. The subject and the teachers-initiated games of tag and chase. This student retained her wearable cane and was reported to be wearing it most of the day for 6 months after the trial.

\section{EXPERIMENT 4-HOW WILL STAKEHOLDERS (FAMILY AND EDUCATORS) EVALUATE WEARABLE CANE AND APP (WCA) SYSTEM USABILITY?}

\section{Background}

The project investigated how to integrate the wearable cane with a computer app. The purpose of this study was to explore 
stakeholders' experiences and comments when employing mock app and cane system separately and together.

\section{Method \\ Sample}

Thirteen participants with SVI\&B aged (28-48 months, $\overline{\mathrm{x}}=33.88$ months), family members $(n=9)$ and O\&M specialists $(n=$ 7) provided feasibility and usability data on the wearable cane and instructional app over 5 months. The 13 participants were selected by their teachers to be included; their teachers reported the participants exhibited mild to severe developmental delays in motor, concepts, language, and social skills. However, no formal tests were conducted by the project.

\section{Measures}

Family members and professionals' statements while using and just after using the mock app were collected on digital video. A week later, an Experience User Designer conducted followup interviews with families and professionals regarding broader topics related to their more global needs and experiences. All interactions with the wearable cane and app prototypes were recorded and coded for content. Inter-rater reliability was not established.

\section{Procedures}

Mock-app trials consisted of a family member activating the mock-app and the participants responding to route destination and activity guides that were spoken by the app in a kid-friendly voice. The mock app provided families with examples of what to say to aid in practicing O\&M activities with their children with SVI\&B who moved about wearing prototype canes.

\section{Results and Discussion \\ Family and Professional Statements}

All family members agreed with the statement that an app designed to help them provide additional O\&M support outside of the O\&M lesson was needed. Five of the seven O\&M professionals who used the mock-app found it was innovative and encouraged its further development. All O\&M specialists were highly interested in a family-centered app that collected assessment data on the child's growth and development.

The following statements summarized the adult interview data ( $n=16)$ : (1) a family-facing O\&M instructional app is needed ( $n=16)$; (2) the app should: (a) provide rewards to adults for completing O\&M activities with their child $(n=9)$, (b) provide kid-friendly screens and voices $(n=14)$, (c) offer families insight into the child's current developmental skills $(n=14)$, (d) offer activities that families can easily integrate into their day $(n=12)$, and (e) collect data that can be shared with the family-centered service team members $(n=16)$.

The wearable cane with a hands-free autonomous cane arc has shown great potential benefit for children under five with SVI\&B. Participants expressed interest in a computer application able to support the integration of this new wearable white cane into daily routines.

\section{CONCLUSIONS}

This project succeeded in creating a usable, wearable white cane prototype, which provided consistent path information to learners under five with SVI\&B. When wearing their canes subjects with visual impairment show noticeable improvements in their pace and gait. They walked faster, more erect and in straight lines. The wearable cane functioned effectively on demanding terrain such as found on rural farms and playgrounds. This research project identified the need for a family-centered computer application to support families and professionals in integrating the wearable white cane into daily activities and routines.

The participants easily learned to manipulate the two cane shafts of the wearable cane to locate a clear path. One student with SVI\&B requested to wear her cane home and continued to wear it at 1 and 2-month follow-up. Students wearing the canes were observed to be more animated and playful. The more uneven the terrain the more participants with SVI\&B wanted to maintain wearing their canes. The adoption of the wearable canes by participants, immediately, and with minimal instruction, is in contrast with their lack of ability to use long canes to obtain vital path information after many months of regular instruction. None of the pre-school learners were able to manipulate their long canes effectively on paths in school and outside to obtain consistent NSW.

When wearing their custom-fitted canes, participants spent more time investigating and discussing their environment; they were also more likely to self-initiate exploration of their environment to objectives they self-selected. A common observation was that the children with SVI\&B were walking straight, meaning they were walking with purpose toward people, objects and places compared to when they were observed walking without a mobility tool or when using a long cane and appeared to meander and frequently changed direction.

Some of the multi-sensory feedback from the wearable cane was evident in the outward appearance of the children with SVI\&B's ambulation strategies. The children wearing the cane tended to walk forward until an object, level, or surface change halted them. Adults found they were unaccustomed to seeing the children with SVI\&B suddenly stop, purposefully change direction, actively and independently avoid hazards, capably remain on the sidewalk and figuring out how to get the cane tips unstuck from furniture or bushes.

The teachers' postures were also straighter and more natural as they rarely bent over to reposition the wearable cane, compared to when the long cane was used. Teachers were also able to stand further away and observe their students' ambulation as they grew in confidence that their students were responding predictably to the tactile path information provided by the cane.

Despite the teachers' verbal observations documenting improvements in their students with SV\&B motor and other skills when wearing their canes compared to using long canes; the they did not agree that wearing the cane was an effective tool for this age group. They argued that the wearable cane prototype would limit the effectiveness of their long cane instruction. 
The view of the authors is that the decision to withhold wearable canes from learners aged five and younger who are SVI\&B is more than just clinical, it an ethical one as well. These extremely vulnerable children are being asked to move about freely despite their being unable to see obstacles in the path ahead.

There is overwhelming scientific evidence that documents the negative outcomes associated with the clinical method that encourages congenitally SVI\&B children aged five and younger to move about as if they can see. The authors believe that to combat these avoidable developmental delays, blind children five and younger should begin wearing their canes as young as possible and they should wear them most of their waking day. This is because path information is a vital life force and is more easily obtained by SVI\&B children when they are provided with constant, independent access to it in sensory forms accessible to them. In addition, early intervention O\&M will become less about attempting to teach the mechanics of cane manipulation, and instead will be able to focus on concept, language and social skill development activities. Young learners who grow up with consistent path preview will also avoid the adverse motor skill delays found in learners with SVI\&B who have been taught to freely navigate without any warning about obstacles in their paths.

Safe mobility is a cross-disciplinary concern. A wearable cane has the potential to enhance a child's movement during other therapies, in the classroom, as well as during experiences outside of school including; on field trips, moving about in playgrounds, at home and in the community. Learners with SVI\&B did not demonstrate the physical or cognitive ability to employ a syncopated long cane arc, despite having received extensive training and practice as part of daily O\&M instruction and practice with the long cane. This is in marked contrast to these subjects quickly making best use of the hands-free autonomous cane arc. Children under five with SVI\&B showed a preference for wearing the cane across terrain conditions. The WCA System was found to be a usable prototype with potential to innovate the O\&M curriculum for EI and pre-school learners with SVI\&B.

\section{LIMITATIONS}

The pilot studies participants were a small, heterogeneous population. These studies were focused primarily on the feasibility and usability of the WCA system, additional outcome studies that include younger subjects with SVI\&B are needed. In addition, more formal measures of gait, language, and development should be included in further examinations of a WCA system.

\section{REFERENCES}

Adolph, K. E., Cole, W. G., Komati, M., Garciaguirre, J. S., Badaly, D., Lingeman, J. M., et al. (2012). How do you learn to walk? Thousands of steps and dozens of falls per day. Psychol. Sci. 23, 1387-1394. doi: 10.1177/0956797612446346
The rapid adoption of the wearable cane in almost all of the prototype forms by the subjects and the direct, observable, positive changes in subjects who tested P20 including better posture, faster gait, increased walking purposeful routes, greater levels of communication and fun, age-appropriate social interactions among these subjects, and their teachers were observed when subjects wore their canes and were supported by the directed activities and evaluation data that will 1 day be part of a family-centered computer application.

At the root of the WCA system is consistently safe mobility for blind learners under five. The wearable cane affords them the warning they need and are unable to obtain visually. This study documented that toddlers and pre-school learners who were taught primarily diagonal cane technique, were unable to maintain positioning of the long cane as they ambulated. The automatic arc of the hands-free wearable cane provided them with consistent path information in a sensory language readily available to most learners with SVI\&B including; tactile, kinesthetic, proprioceptive, haptic, echolocated, auditory, and objective perceptic feedback. The wearable cane showed a clear advantage over the long cane in learners under five with SVI\&B.

\section{ETHICS STATEMENT}

This study was carried out in accordance with the recommendations of City University of New York (CUNY) Human Research Protection Program guidelines by the CUNY University Integrated (UI) Human Research Protection Program (HRPP) committee. The protocol was approved by the CUNY UI HRPP committee. All subjects gave written informed consent in accordance with the Declaration of Helsinki. An adult family member provided signed consent for minors.

\section{AUTHOR CONTRIBUTIONS}

GA-Z invented the first prototype, oversaw the research efforts of the team, ran trials, analyzed data, and was first author. $\mathrm{MF}$ and $\mathrm{HB}$ created the wearable cane prototypes using 3-D printer and conducted engineering trials. RW provided research design and reviewed the project and provided editorial support on the article. MB and his lab produced the prototypes, he oversaw all engineering research on design, materials and etc. He played a significant role in the project and this manuscript.

\section{FUNDING}

IES Department of Education Small business innovation research: Phase 1 ED-IES-17-C-0041. 
Bongers, R., Schellingerhout, R., van Grinsven, R., and Smitsman, A. (2002). Variables of the touch technique that influence the safety of cane walkers. $J$. Vis. Impair. Blind. 96, 516-531.

Celeste, M. (2006). Play behaviors and social interactions of a child who is blind: IN theory and practice. J. Vis. Impairment Blindness 100, 75-90. doi: 10.1177/ $0145482 X 0610000203$

Celeste, M., and Grum, D. (2010). Social integration of children with visual impairment: A developmental model. Elementary Educ. Online 9, 11-22.

Deshpande, N., Metter, E. J., and Ferrucci, L. (2011). Sensorimotor and psychosocial correlates of adaptive locomotor performance in older adults. Arch. Phys. Med. Rehabil. 92, 1074-1079. doi: 10.1016/j.apmr.2011.02.006

Eggenberger, P., Tomovic, S., Münzer, T., and de Bruin, E. D. (2017). Older adults must hurry at pedestrian lights! A cross-sectional analysis of preferred and fast walking speed under single- and dual-task conditions. PLoS ONE 12:e182180. doi: 10.1371/journal.pone.0182180

Gazzellini, S., Lispi, M. L., Castelli, E., Trombetti, A., Carniel, S., Vasco, G., et al. (2016). The impact of vision on the dynamic characteristics of the gait: strategies in children with blindness. Exp. Brain Res. 234, 2619-2627. doi: 10.1007/s00221-016-4666-9

Glaser, B., and Strauss, A. (1967). The Discovery of Grounded Theory: Strategies for Qualitative Research. Piscataway, NJ: Transaction publishers. doi: 10.1097/00006199-196807000-00014

Glaser, B. G. (1998). Doing Grounded Theory: Issues and Discussions. Mill Valley, CA: Sociology Press.

Hallemans, A., Ortibus, E., Truijen, S., and Meire, F. (2011). Development of independent locomotion in children with a severe visual impairment. Res. Dev. Disabil. 32, 2069-2074. doi: 10.1016/j.ridd.2011.08.017

Hatton, D. D., Ivy, S. E., and Boyer, C. (2013). Severe visual impairments in infants and toddlers in the United States. J. Vis. Impair. Blind. 107, 325-336. doi: $10.1177 / 0145482 \mathrm{X} 1310700502$

Kim, D. S., Emerson, R. W., and Naghshineh, K. (2017). Effect of cane length and swing arc width on drop-off and obstacle detection with the long cane. $\mathrm{Br}$. Vis. Impair. 35, 217-231. doi: 10.1177/0264619617700936
Leversen, J. S., Haga, M., and Sigmundsson, H. (2012). From children to adults: motor performance across the life-span. PLoS ONE 7:e38830. doi: 10.1371/journal.pone.0038830

Salive, M. E., Guralnik, J., Glynn, R. J., Christen, W., Wallace, R. B., Ostfeld, A. M. et al. (1994). Association of visual impairment with mobility and physical function. J. Am. Geriatr. Soc. 42, 287-292. doi: 10.1111/j.1532-5415.1994.tb01753.x

St. Onge, P. M., Parish, L. E., Farquar, C. A., Bumgardner, B. A., Breslin, C. M., and Rudisill, M. E. (2007). Accelerometer measurement validation: association of accelerometer data with acceleration units with students engaged in and the instructors of a mastery motivation physical play program. J. Sport Exerc. Psychol. 29, S44-S45. doi: 10.1519/JSC.0b013e3181 $876 \mathrm{a} 01$

Subhi, H., Latham, K., Myint, J., and Crossland, M. D. (2017). Functional visual fields: relationship of visual field areas to self-reported function. Ophthalm. Physiol. Optics 37, 399-408. doi: 10.1111/opo.12362

West, S. K., Rubin, G. S., Broman, A. T., Muñoz, B., Bandeen-Roche, K., and Turano, K. (2002). How does visual impairment affect performance on tasks of everyday life?: the SEE project. Arch. Ophthalmol. 120, 774-780. doi: 10.1001/archopht.120.6.774

Conflict of Interest Statement: The authors declare that the research was conducted in the absence of any commercial or financial relationships that could be construed as a potential conflict of interest.

Copyright (c) 2019 Ambrose-Zaken, FallahRad, Bernstein, Wall Emerson and Bikson. This is an open-access article distributed under the terms of the Creative Commons Attribution License (CC BY). The use, distribution or reproduction in other forums is permitted, provided the original author(s) and the copyright owner(s) are credited and that the original publication in this journal is cited, in accordance with accepted academic practice. No use, distribution or reproduction is permitted which does not comply with these terms. 